\title{
Impact of Medium of Instruction on Life Skills of school students
}

\author{
Mukta A. Karamadi \\ Vijayalaxmi A. Aminabhavi \\ ${ }^{1}$ Associate Professor, Dhempe College of Arts \&Science, Panaji -Goa. \\ ${ }^{2}$ Professor, Chairperson, Department of Psychology, Karnatak University, Dharwad-Karnataka. \\ E-mail-mukta_ak@yahoo.com
}

\begin{abstract}
The present study aimed at assessing the level of life skills of school students and to investigate the impact of medium of instruction on life skills as well as gender differences in life skills. The sample comprised of 200 school students in the age group of 13-14 years from schools in Panaji-Goa. It was hypothesized that the students who had their primary education in mother tongue medium and those who had studied in English medium do not differ significantly on measures of life skills. A null hypothesis was proposed with regard to gender differences in life skills. To measure the life skills of the students Psychosocial Competence Scale was used. It was found that most of the students (73\%) have average level of life skills, a few (11\%) have high level of life skills and some of them (16\%) have a low level of life skills. The results indicated the need for inclusion of life skill training programme in school curriculum for mental wellbeing of the students. The obtained t-value revealed that the students with primary education in English medium have significantly higher level of life skills than those who had primary education in their mother tongue medium. It was also found that the female students have significantly higher level of life skills than the male students.
\end{abstract}

Key Words: medium of instruction, life skills, gender.

\section{INTRODUCTION}

The medium of instruction is the language used by the teacher to teach the content subjects. An English medium education system is the one that uses English as the primary medium of instruction, particularly where English is not the mother tongue of the students. Mother tongue medium education refers to a system where the medium of instruction is the first language (mother tongue) or home language of the students. SrivastavaandKhatoon in their paper reported that, there is a very strong section of opinion favouring mother tongue (MT) as the medium of instruction (MOI) for every child [1]. At the time of entering school, a child's competence to understand and manipulate his MT is well developed. One of the most important principles of educational psychology is first to ascertain what the child already knows, and then to start accordingly [2]. The child knows well his MT. Therefore, if the MT becomes the MOI, education becomes more 
meaningful where the cognitive faculties are ready to receive and act, transfer and integrate.Supporting the plea for making MT of a child his MOI, the UNESCO report (1953) [3] states, "Psychologically, it is the system of meaningful signs that his mind works automatically for expression and understanding, Sociologically it is the meaning of identification among the members of the community to which he belongs, Educationally he learns more quickly through it than through an unfamiliar linguistic medium".

However to prepare the young people for a globalised world, and to keep pace with the increasing spread of English as the world language, many education systems worldwide use English as the Medium of Instruction. Researchers have reported that there has been a lot of research focussing on the effects of bilingual education that is education through a language other than the mother tongue of the child, the results of which reveal an important divide [4]. Policymakers [3] as well as researchers [5-7] feel that learning in two languages will slow the cognitive development and consequently have long term negative effects on the educational achievements of the children. Until early 1980s, the literature was dominated by negative outcomes of bilingual education which was viewed as a source of developmental problems or delays.

On the other hand, more recent studies in many disciplines namely, education, psycholinguistics, psychology, speech and hearing sciences and neurosciences present a different view emphasizing the positive consequences of bilingualism. The studies have revealed that, bilingual education is a great asset to the child and the bilingual child has better awareness of language differences, is better at learning new languages and possesses advantages in intelligence and cognitive growth [8-11]. Researchers have also found that there is a remarkable difference in the cognitive systems of bilingually educated children and mono-lingually educated children (educated through mother tongue). Learning, speaking and using two languages may affect fundamental aspects of cognitive and neural development, potentially influencing the way those systems learn and represent information [12-15]. Moreover, a number of studies conducted in India also have reported either beneficial effect or no detrimental effect on the cognitive abilities and academic performance of the child if he is educated through a medium other than his own mother tongue.

Sunitha and Khadi [16] investigated the academic learning environment at home and school, of coeducational high school students and its influence on academic achievement, and revealed that students from English medium schools were significantly higher in student's involvement, these schools had higher qualified teachers, received significantly better parental encouragement and care, had significantly better facilities in home and had significantly better academic achievement than students from Kannada medium schools.Ramasamy [17] has quoted in his paper the following studies: Anand[18] compared Kannada and English medium students and found the former significantly superior in verbal intelligence and achievement and the latter in nonverbal intelligence. A study conducted by Srivastava and Khatoon[1] showed that the English medium students scored significantly better than the Kannada medium students on the measures of nonverbal intelligence and the three dimensions of verbal creativity, namely, fluency, flexibility, and originality. However, when the school related measures were controlled, there was hardly any difference between the two streams. Srivastava and Ramasamy [19] found that the students in the English medium group scored higher than others on the nonverbal intelligence tests. The mother tongue medium group scored higher in verbal creativity. Yela [20] had argued that since children taught through their mother tongue use simple and direct strategies as opposed to the complex and indirect ones of the bilingual children, the former would perform significantly better than the latter on verbal problems involving reflective thoughts. 
Chan [21] investigated how medium of instruction as a factor interacts with relevant socio-cultural contextual factors to create impact on the attitudes, motivation and academic performance of secondary school children in Hong Kong. They found that in a context where the differences between the two learning media are substantial in terms of status and educational values, the MOI streaming had a unique and more positive impact on students, studying through the high power second language (i.e. English). They had more favourable attitudes towards English, higher level of L2 motivation, better self-concept and an inclination to a higher level of internality.

\section{Life Skills}

The World Health Organization defines Life skills as "the abilities for adaptive and positive behaviors that enable individuals to deal effectively with the demands and challenges of everyday life" [22]. According to the WHO papers on mental health, 'nearly one in five children will have an emotional/behavioural disorder at some time during their youth regardless of where they live or how well to do they are'. Emotionally disturbed children exhibit their impairment in a variety of ways such as failing academically, having poor self-images and poor relationships with peers and adults.Additionally, they may have little respect for the law of their society. Academic failure and social rejection have a lasting consequence, as failure to learn in school, limits a person's chance to succeed in the future [23]. Therefore improvement of mental health of children and prevention of childhood emotional problems is very crucial and this can be achieved by teaching the school children the essentials of mental health and giving training to enhance life skills.

The core set of life skills which help in promoting health and well-being of children and adolescents are: Decision making, Problem solving, Creative thinking, Critical thinking, Effective communication, Interpersonal relationship skills, Self-awareness, Empathy, Coping with emotions and Coping with stress.The school is a good place to introduce life skills programmes, as the school years are important developmental years in an individual's life. In school, besides academics children also learn social skills and encounter authority other than their parents who can provide guidance, support and direction to them. Furthermore, schools have a great influence on the stake holders i.e. children and their families. For these reasons the school is an ideal institution for life skills intervention. Researchers [24] evaluated implementation and impact of the NIMHANS model of life skills education program, with the aim of mental health promotion among adolescents in schools, using life skills education and teachers as life skill educators. The adolescents in the program had significantly better selfesteem, perceived adequate coping, and better adjustment generally, specifically with teachers in school, and pro social behaviour. There was no difference between the two groups in psychopathology and adjustment at home and with peers. Life skill educatorteachers also perceived positive changes in the students in the program in class room behaviour and interaction.

Aparna and Raakhee [25] emphasized the importance of life skills, and the benefits of imparting life skill education in school curriculum. The benefits include: Promotion of self esteem, peace education, self confidenceetc [26], Prevention of antisocial activities and behaviour [27-28] andhelps in the promotion of general wellbeing and primary prevention [29-31]. Life skills enable individuals to translate knowledge, attitudes and values into actual abilities and enable individuals to behave in healthy ways. Results of research studies also prove that life skill education improves the academic performance of individuals [32]. 
There are numerous studies which have investigated the effects of MOI on different variables such as academic achievement, cognitive processes, selfefficacy, achievement motivation etc. But studies evaluating the impact of MOI on life skills are almost negligent. Therefore the present study is taken up with the following objectives viz. to assess the level of life skills of the school students and to investigate the impact of medium of instruction on life skills of school students. Another aim is to analyse the gender differences with regard to various dimensions of life skills.

\section{Hypotheses}

- The students with primary education in their mother tongue medium do not differ significantly in their life skills, from those who had primary education in English medium.

- The male and female students do not differ significantly in their life skills.

\section{METHODOLOGY}

\section{Sample}

A purposive sample of 200 students studying in $8^{\text {th }}$ standard was selected. The sample comprised of 100 students with primary education in their mother tongue (Marathi) medium and 100 students with primary education in English medium. Both the groups consisted of equal number of boys and girls. The students were selected from English medium coeducational schools in Panaji city, North Goa.

To measure the life skills of the students Psychosocial Competence Scale constructed by Dindigal and Aminabhavi [33] was used. The scale consists of 100 items, focusing on 10 different life skills such as problem solving, decision making, critical thinking, empathy, self-awareness, coping with emotions, coping with stress, interpersonal relations and effective communication. This is a Likert type scale having 5 response categories. There are 75 positively keyed items and 25 negatively keyed items. The positively keyed items are assigned scores from 1 to 5 whereas the negative items are scored in reverse order that is 5 to 1 . Therefore the lower score indicates higher competence and vice versa. The authors have reported that the scale as a whole has split-half reliability coefficient by Cronbach alpha $=0.88$, Spearman-Brown coefficient $=0.71$ and Guttmann's split-half coefficient $=0.71(P<0.001)$. Similarly the concurrent validity of all sub scales ranges from 0.38-0.76 $(P<0.001)$.

The primary data for the present study has been collected from 200 students. The purpose and nature of the study was explained to the Headmaster/Headmistress of the schools and permission to administer the scale to the students was sought. After establishing a rapport with the students, Ahuja's Group Intelligence Test [34] was administered to a group of 30-35 students at a time. And the final data was collected from only those students whose I.Q scores fell in the range of 90 to109 i.e. average intelligence. After establishing a rapport with the selected students the psychosocial competence scale was administered to a group of 20-25 students at a time.

\section{Statistical Analysis}

The data was analysed with percentages, descriptive statistics and applying the t-test where appropriate. 


\section{RESULTS}

The results given in Table 1 show that among the total sample of 200 students, most of the students $(73 \%)$ have average level of life skills, few students $(11 \%)$ show a high level of life skills and some of them (16\%) possess a low level of life skills.Among the students who had their primary education in their mother tongue (Marathi) medium, $75 \%$ show average level of life skills, $19 \%$ show a low level of life skills and $6 \%$ show a high level of life skills. Among the students who had studied in English medium schools during their primary grades, $71 \%$ show average level of life skills, $16 \%$ show a high level of life skills and $13 \%$ of students have low level of life skills.Overall it can be observed that very few students possess high level of life skills, whereas most of them have average and few of them have low level of life skills. The results indicate that there is a need for enhancing the life skills of students through some means such as life skill education programmes in schools.

Table-1: Students with Low, Average and High Level of Life Skills

\begin{tabular}{|l|ccc|}
\hline Groups & $\begin{array}{l}\text { Low level of life } \\
\text { skills }\end{array}$ & $\begin{array}{l}\text { Average level of } \\
\text { life skills }\end{array}$ & $\begin{array}{l}\text { High level of life } \\
\text { skills }\end{array}$ \\
\hline $\begin{array}{l}\text { Mother tongue } \\
\text { MOI }(\mathbf{N = 1 0 0 )}\end{array}$ & $19 \%$ & $75 \%$ & $6 \%$ \\
\hline $\begin{array}{l}\text { English MOI } \\
(\mathbf{N}=\mathbf{1 0 0})\end{array}$ & $13 \%$ & $71 \%$ & $16 \%$ \\
\hline Total $(\mathbf{N = 2 0 0 )}$ & $16 \%$ & $73 \%$ & $11 \%$ \\
\hline
\end{tabular}

The obtained t-values shown in Table 2 reveal that the students with the primary education in English medium and those with the primary education in their mother tongue differ significantly from each other in some of the dimensions and overall psychosocial competence. The difference between the two groups is very highly significant $(P<0.001)$, in the dimensions of self-awareness $(t=3.75)$ coping with emotions $(t=3.72)$ and coping with stress $(t=8.61)$. In the dimension of empathy as well as overall psychosocial competence, the difference between the two groups is highly significant $(P<0.01)$ i.e. $t=2.80$ and $t=2.81$ respectively. It can also be observed that in all the dimensions except critical thinking, the mean scores of mother tongue medium students are higher than those of English medium students. Therefore it can be noted that the students with primary education in English medium possess higher level of life skills than their counter parts. (Higher score indicates lower life skills and vice versa).

The difference between boys and girls is very highly significant in the dimension of empathy $(t=4.63 ; P<0.001)$. Further, the difference between boys and girls is highly significant in the dimension of self awareness $(t=2.66 ; P<0.01)$. The results also show that the two groups of students differ significantly $(P<0.05)$, in the dimensions of inter personal relations skill $(t=2.01)$ effective communication $(t=2.19)$ as well as overall psychosocial competence $(t=2.17)$.It can also be observed that in all the dimensions except decision making, the mean scores of male students are higher than those of female students (Table 3 ). 
Table2 : Various Dimensions and Overall PsychosocialCompetence Scores of Students

\begin{tabular}{|cccccc|}
\hline & \multicolumn{4}{l}{$\begin{array}{l}\text { Mother tongue } \\
\text { Medium Primary } \\
\text { Education }\end{array}$} & $\begin{array}{l}\text { English Medium } \\
\text { Primary Education }\end{array}$ \\
\hline Dimensions & Mean & SD & Mean & SD & t-value \\
\hline ProblemSolving & 24 & 4.5 & 23 & 5 & 1.49 \\
\hline Decision Making & 28 & 4.4 & 27 & 4.9 & 1.52 \\
\hline Critical Thinking & 24 & 5.8 & 24 & 11 & 0.00 \\
\hline Creative Thinking & 24 & 4.8 & 23 & 5.1 & 1.43 \\
\hline Empathy & 23 & 5.1 & 21 & 5 & $2.80^{* *}$ \\
\hline Self Awareness & 23 & 6 & 20 & 5.3 & $3.75^{* * *}$ \\
\hline Coping with Emotions & 28 & 7 & 25 & 4 & $3.72^{* * *}$ \\
\hline Coping with Stress & 26 & 5.7 & 19 & 5.8 & $8.61^{* * *}$ \\
\hline Interpersonal Relations & 23 & 4.9 & 22 & 4.9 & 1.44 \\
\hline Effective Communication & 23 & 5.6 & 22 & 5.6 & 1.26 \\
\hline $\begin{array}{c}\text { Overall Psychosocial } \\
\text { Competence }\end{array}$ & 309 & 29 & 297 & 31.3 & $2.81^{* *}$ \\
\hline
\end{tabular}

$(* * p<0.01 * * * p<0.001)$

Table-3: Various Dimensions and OverallPsychosocial Competence Scores of Male and Female Students

\begin{tabular}{|c|ccccc|}
\hline & \multicolumn{3}{l}{ Male students } & \multicolumn{3}{l}{ Female students } & \\
\hline Dimensions & Mean & SD & Mean & SD & t-value \\
\hline Problem Solving & 24 & 4.648 & 23.556 & 4.949 & 0.65 \\
\hline Decision Making & 27.185 & 4.619 & 27.806 & 4.782 & 0.93 \\
\hline Critical Thinking & 24.380 & 11.435 & 23.398 & 5.726 & 0.77 \\
\hline Creative Thinking & 23.609 & 5.144 & 22.546 & 4.760 & 1.52 \\
\hline Empathy & 23.554 & 5.217 & 20.296 & 4.715 & $4.63^{* * *}$ \\
\hline Self-Awareness & 22.337 & 6.039 & 20.176 & 5.463 & $2.66^{* *}$ \\
\hline Coping with Emotions & 26.630 & 7.255 & 26.352 & 4.149 & 0.33 \\
\hline Coping with Stress & 22.859 & 6.601 & 22 & 6.565 & 0.92 \\
\hline Interpersonal Relations & 23.467 & 4.649 & 22.074 & 5.126 & $2.01^{*}$ \\
\hline Effective Communication & 23.446 & 5.760 & 21.712 & 5.453 & $2.19^{*}$ \\
\hline $\begin{array}{c}\text { Overall Psychosocial } \\
\text { Competence }\end{array}$ & 308.076 & 31.758 & 298.713 & 29.253 & $2.17^{*}$ \\
\hline
\end{tabular}

$(* p<0.05, * * p<0.01, * * * p<0.001)$

\section{DISCUSSION}

Education aims at an all-round development of the students i.e. academic excellence and enhancement of psychosocial skills in the students. Moreover, schools are crucial in building or undermining self esteem and sense of competence as teachers and peers exert great influence on the development ofself esteem of school children. The education system needs to enable children to deal effectively with the challenges of life and 
empower them to build their lives. To enable these behavioural transformations in children, the system needs to enrich the school curriculum with a highly effective life skills training program. Life skill education promotes mental well-being in people and equips them to face the realities of life, and is crucial in today's world. The results of the present study reveal that very few students show above average life skills most of the students have average life skills and some of them have below average life skills. This indicates that there is a need for an interactive educational programme for life skills enhancement in schools to promote mental well-being of the adolescents.

Many researchers have found the positive effects of life skill training programmes. They have concluded that life skills training has a positive effect on social development, emotional and social adjustment and compatibility [35]. Others have revealed that life skill training improved self-esteem, emotional adjustment, educational adjustment, total adjustment and empathy of adolescents [36].The results of the present study have revealed that the students with primary education in English medium have significantly higher level of life skills than those with primary education in their mother tongue medium. These results are in line with earlier research findings. Tiwari found that the children attending English medium schools were emotionally more intelligent than Hindi and mixed medium school children. He also revealed that the physical and psychological environment at home and school correlated significantly with emotional intelligence [37]. Indian research has revealed that the students from English medium schools had better infrastructure and learning environment in schools as well as home and received significantly better parental encouragement and care than Kannada medium schools [16].

The children who study in English medium schools from early years develop the ability to converse fluently in English which enhances their self confidence, communication skills and self esteem. This in turn might facilitate the development of various other life skills as they are all interlinked. Further these students usually come from families with higher socio economic status and have access to better facilities, important resources and good exposures which facilitate their overall development. The parents who are privileged educationally, socially and economically, promote higher level of achievement in their children. They also provide psychological support for their children through enriched atmosphere that promote and encourage the development of skills required for success at school [38-39].

The present study has also revealed that the girls have significantly higher level of life skills compared to the boys, which is in support of earlier findings [40].This gender difference is perhaps due to the fact that the socialization process in Indian culture emphasises gender typing for girls more than for boys. The girls are expected and groomed to be more empathetic, conscious about self, as well as good in interpersonal relations, communication skills etc. In this study we find that girls have significantly higher level of life skills than the boys in these dimensions. These findings are in support of a study conducted by Anuradha [41] where the girls scored higher than the boys in skills such as self awareness, critical thinking and empathy.

Certain conclusions could be drawn from our findings. Most of the students have average life skills and some of them have lower level of life skills, and few of them show higher level of life skills. The students with primary education in English medium have significantly higher level of life skills in the dimensions of self awareness, coping with emotions and coping with stress, empathy as well as overall psychosocial competence, than those with primary education in their mother tongue medium. The 
female students have significantly higher level of life skills than the male students in the dimensions of empathy, self awareness, inter personal relations, effective communication as well as overall psychosocial competence.

\section{REFERENCES}

1. Srivastava AK, Khatoon R. Effect of difference between mother tongue and another language as medium of instruction on achievement, mental ability and creativity of the VIII standard children[Internet]. Available from: http://www.ciilebooks.net/html/bilingualism/part3.html

2. Ausubel DP. Educational Psychology : a cognitive view. Holt, Rinehart and Winston ; 1968.

3. UNESCO. The use of vernacular languages in education. Monograph on fundamental education [Internet]. UNESCO; $1953 . \quad$ Available from: http://unesdoc.unesco.org/images/0000/000028/002897eb.pdf.

4. Senapati P, Patnaik N, Dash M. Role of medium of instruction on the development of cognitive processes. Journal of Education and Practice [Internet]. 2012; Vol 3, No 3. Available from: http://www.iiste.org/Journals/index.php/JEP/article/view/1162/1083.

5. Mohanty AK. Psychological consequences of mother tongue maintenance and the language of literacy for the minorities in India. Psychol \& Dev Societies 1989; 2(1):31-51.

6. Mwamwenda TS. Educational Psychology : An African Perspective. Durban: Butterworths ; 2008.

7. Pattanayak DP. Language, education and culture. Mysore: Central Institute of Indian Languages; 1991.

8. Coneau L, Genesee F, Mendelson M. Bilingual children's repairs of breakdowns in communication. J Child Lang 2007;34:159-74.

9. Roseberry- Mckibbin C, Brice A. Acquiring English as a second language.American SpeechLanguage-Hearing Association Leader 2000;5:4-6.

10. Siegal M, Iozzi L. Surian L. Bilingualism and conversational understanding. Cognition 2009;110:115-22.

11. Varkuti A. Biology-based analogous reasoning in the target language in Hungarian English high schools. A Biologiatanitasa 2009;XVIII:3-14.

12. Bialystok E. Cognitive complexity and attention control in the bilingual mind. Child Dev 1999;70:636-44.

13. Bialystok E, Craik FIM, Klein R, Viswanathan M. Bilingualism, aging and cognitive control: Evidence from the Simon task. Psychology and Aging 2004;19:290-303. Available from: http://www.sakkyndig.com/psykologi/artvit/bialystok2004.pdf.

14. Bialystok E, Martin MM. Attention and inhibition in bilingual children: Evidence from the dimensional change card sort task. Developmental Science [Internet]. 2004;7:325-39. Available from: http://psychology.illinoisstate.edu/cbs/readings/BialystokMartin.pdf.

15. Yoshida $\mathrm{H}$. The cognitive consequences of early bilingualism. Zero to Three [Internet]. 2008;29(2):26-30.

Available from: http://www.uh.edu/class/psychology/devpsych/docs/ZeroYoshida.pdf

16. Sunitha NH, Khadi PB. Academic learning environment of students from English and Kannada medium high schools. Karnataka J Agric Sci 2007;20(4):827-30.

17. Ramasamy $\mathrm{K}$. Mother tongue and medium of instruction - A continuing battle. Language in India [Internet]. 2001 Oct; Vol. 1:6:[about 2p]. Available from: http://www.languageinindia.com/oct2001/ramasamyk1.html.

18. Anand CL. The study of the effect of socio economic environment and medium of instruction on the mental abilities and the academic achievement of children in Mysore state [dissertation]. Mysore University; 1971 Sept.

19. SrivastavaAK, Ramasamy K. A study on the effect of medium of instruction, socioeconomic status and sex on academic achievement, intelligence and creativity. CIIL, Mysore; 1986. 
20. Yela M. Verbal comprehension and bilingualism. Revista de Psycologia Gen Aplicada 1975;30:1039-46.

21. Chan Rita Lai-ying. Context and impact of medium of instruction on attitudes, motivation and academic performance: Secondary school children in Hong Kong [Doctoral thesis]. Durham University; 2007. Available from: http://etheses.dur.ac.uk/2851.

22. World Health Organization. Life skills education: planning for research. Geneva, WHO. $1996 ; 72 \mathrm{p}$.

23. Hendren R, BirellWeisen R, Orley JH. WHO papers on mental health [Internet]. WHO; 1994. Available from: http://www.actionresearch.net/living/rawalpdf/Chapter4.pdf.

24. Srikala B, Kumar KVK. Empowering adolescents with life skills education in schools School mental health program: Does it work?. Indian J Psychiatry 2010; 52(4):344-9.

25. Aparna N, Raakhee AS. Life skill education for adolescents: its relevance and importance. GESJ:Education Science and Psychology 2011;2:19-25.

26. TACADE. Skills for the primary school child: Promoting the protection of children. UK:Salford; 1990

27. Botvin GJ, Baker E, Botvin EM, Filazzola AD, Millman RB. Prevention of alcohol misuse through the development of personal and social competence: A pilot study. J Stud Alcohol 1984;45:550-2.

28. Pentz MA. Prevention of adolescent substance abuse through social skills development. In Glynn TJ.et al. (Eds.) Preventing adolescent drug abuse: Intervention strategies, NIDA Research Monograph 1983;47:195-235.

29. Errecart MT, Walberg HJ, Ross JG, Gold RS, Fielder JF, Kolbe LJ. Effectiveness of teenage health teaching modules. J School Health 1991;61(1):290-5.

30. Perry CL, Kelder SH. Models of effective prevention. J Adolesc Health 1992;13(5): 355-63.

31. Caplan M, Weissberg RP, Grober JS, Jacoby C. Social competence promotion with inner city and suburban young adolescents: Effects on social adjustment and alcohol use. J Consult Clin Psychol 1992;60(1):56-63.

32. Weissberg RP, Caplan MZ, Sivo PJ. A new conceptual framework for establishing schoolbased social competence promotion programs. In Bond. L.A. and Compas. B. E. (Eds.) Primary prevention and promotion in schools. Newbury Park, CA: Sage; 1984

33. Dindigal A, Aminabhavi VA. Impact of life skills education on psychosocial competence of adolescents [PhD thesis]. Karnatak University, Dharwad; 2007 (unpublished).

34. Ahuja GC. Group test of intelligence. National Psychological Corporation, Agra; 2009.

35. Roodbari Z, Sahdipoor E, Ghale S. The study of the effect of life skill training on social development, emotional and social compatibility among first- grade female students of high school in Neka city. Indian Journal of Fundamental and Applied Life Sciences 2013;3:382-90.

36. Yadav $\mathrm{P}$, Iqbal $\mathrm{N}$. Impact of life skill training on self-esteem, adjustment and empathy among adolescents. J Indian Acad Appl Psychol 2009;35:61-70.

37. Tiwari PSN. Environmental quality and emotional intelligence. Indian J Soc Sci Res 2011;8(1-2):48-56.

38. Williams T. Participation in education. Australian Council for Educational Research, Hawthorn; 1987

39. Williams TM, Long PC, Hayden M. (1993). Year 12 in the 1980s, AGPS, Canberra.

40. Amiri F, Ajilchi B, Begi A. The role of attachment styles and the knowledge of life skills according to gender in students of Kermanshah Razi University. European J Exp Biol 2013;3(5):577-80.

41. Anuradha K. Assessment of life skills among adolescents. Int J Sci Res 2014;3(2):110-4.

Acknowledgements - Nil

Conflict of Interest - Nil

Funding - Nil. 